\title{
200 volumes in 90 years
}

\author{
Friedrich G. Barth
}

Published online: 25 December 2013

(C) Springer-Verlag Berlin Heidelberg 2013

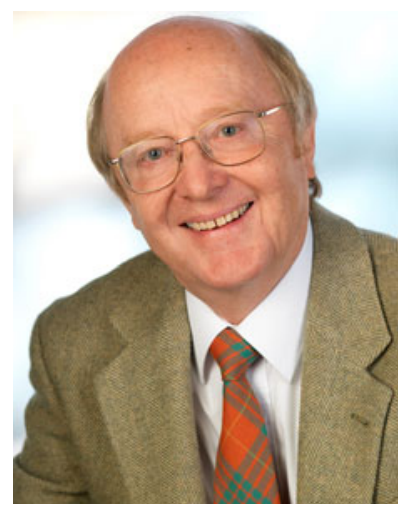

of them had an average of as many as 48 pages. All papers came from German universities, except a study by Hubertus Johannes Vonk Jr of the University of Utrecht, which was about phagocytosis in oysters. German then was the exclusive language of communication. By December 2013 last year's volume 199 had close to 100 articles on a total of about 1,000 pages. Taking together all volumes so far published the Journal communicated the impressive number of 8,640 articles in 989 issues. Now, in 2014, a proudly presented 200th volume underlines the long and successful history of what began 90 years ago.

Friedrich G. Barth

\section{The beginning}

It was around Easter 1924 when the first issue of this Journal appeared as Zeitschrift für vergleichende Physiologie in section $\mathrm{C}$ of the Zeitschrift für wissenschaftliche Biologie. Karl von Frisch, at that time working at the Zoology Institute of the University of Breslau in Germany (now Wroclaw, Poland), had convinced Ferdinand Springer, the publisher, that the increasing number of publications on topics of comparative physiology should have their own journal. He was supported by Alfred Kühn of the University of Göttingen, Germany, as the second main editor. Karl von Frisch and Alfred Kühn had a competent Editorial Board of 25 honorable professors of German universities. Volume 1 contained 13 contributions on 624 printed pages. Thus, each

F. G. Barth ( $\square)$

Department for Neurobiology, Life Sciences, University of Vienna, Althanstr.14, 1090 Vienna, Austria

e-mail: friedrich.g.barth@univie.ac.at

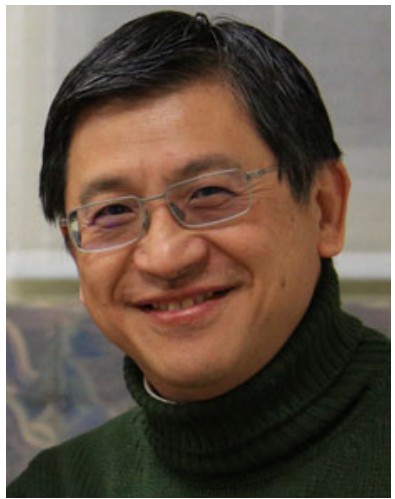

Kentaro Arikawa

\section{Going international}

There were some important changes along the Journal's way. In 1972, 48 years after its first appearance, the Zeitschrift für vergleichende Physiologie underlined its ambitions on an international level by changing its title to Journal of Comparative Physiology (J Comp Physiol). More importantly, from now on publications were in 
English only, following the international trend that made English the lingua franca of science. As a consequence of the enormous science boom after World War II and the increasing specialization of the work presented in the manuscripts, an increasing number of the papers submitted asked for the evaluation and judgment by experts outside the editorial board. International peer reviewing of all manuscripts received from now on has been a strict rule. Apart from strengthening the Journal's quality, the interaction with numerous experts all around the world also promoted the international standing of the Journal. In 2012, $40 \%$ of the accepted manuscripts came from Europe, $35 \%$ from the Americas and $25 \%$ from the Asia-Pacific region. In the same year more than 8,000 institutions had access to the Journal of Comparative Physiology (part A, see below) via online agreements, which illustrates the Journal's high visibility and exposure. During the past decade we published some 100 manuscripts on roughly 1,000 printed pages every year. The unselfish assistance of our many reviewers continues to be an indispensable condition for our Journal's success. It is greatly appreciated.

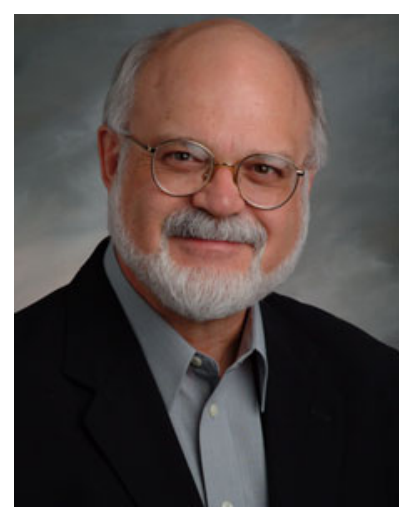

John G. Hildebrand

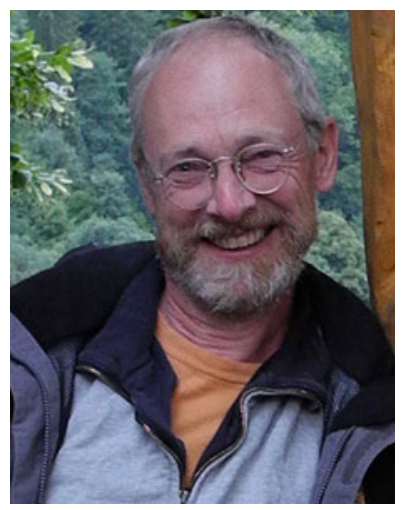

Uwe Homberg

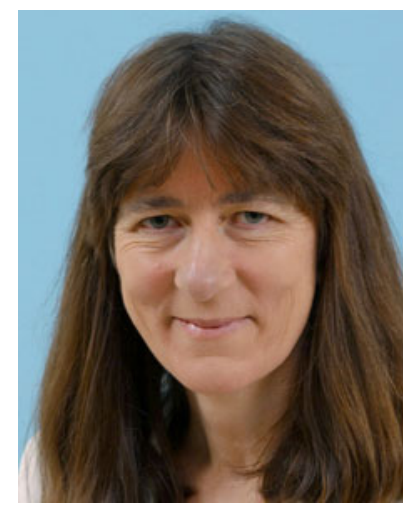

Alison R. Mercer

\section{Two journals out of one}

The increasing specialization and diversification of scientific research, to a large extent due to the availability of new technologies, first was taken into account by having two sections within the same journal (starting with volume 93 in 1974), namely "A. Sensory, Neural and Behavioral Physiology" and "B. Metabolic and Transport Functions". In 1984 this then led to a complete separation into two journals, starting with volume 154. From then on there was the "Journal of Comparative Physiology A-Sensory, Neural, and Behavioral Physiology" and the "Journal of Comparative Physiology B-Biochemical, Systemic, and Environmental Physiology". Again reflecting new developments part A has now "Neuroethology" added to its subtitle on the cover page, whereas the subtitle of part B reads "Biochemical, Systems, and Environmental Physiology".

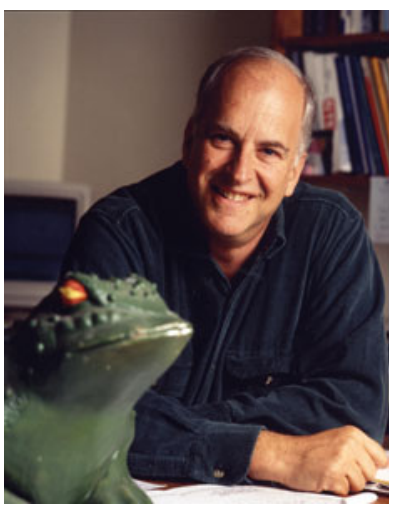

Peter M. Narins 


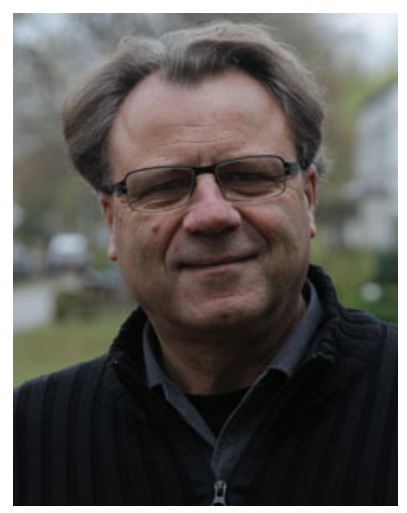

Hans-Joachim Pflüger

\section{The editors: managing and associate}

Despite the long history of the Journal the managing editors changed surprisingly rarely. Up to now there have been only three of them. Karl von Frisch was strongly committed to "his" Journal for many decades. Honoring him at the occasion of his 90th birthday in 1976, Hansjochem Autrum, who succeeded him as Chief Editor in 1960, wrote that von Frisch still was as active as ever and that his advice and criticism always hit the nail on the head. More importantly, as Hansjochem Autrum also pointed out, the enormous impact of von Frisch's research was impressively reflected by the fact, that "there is no volume of the Journal which does not contain works which elaborate on his own thoughts, methods and initiatives" (H Autrum 1976, J Comp Physiol 112:1-4). For those familiar with von Frisch's work this has remained true to this very day to a large extent. Hansjochem Autrum was an enormously dedicated and sometimes rigorous Managing Editor for as many as 36 years. By chance, this is the same time span von Frisch had served in the same capacity. As is well known, Hansjochem Autrum and his many students substantially added to a sensory biology, which has a strong bias towards physics. This is reflected by many publications in our Journal. In 1996 I myself took over as the Editor in Chief, going through the transition from print to electronic publishing in 2005 , but with no ambitions to serve for 36 years as well.

Evidently, the Managing Editors or Editors in Chief have never done their editorial work alone. They always have much relied on the unselfish and competent cooperation of the members of the Journal's Editorial Board and also of its Advisory Board. This is true up to this very day and greatly acknowledged. Thus, Alfred Kühn did editorial work for 20 years until 1944. Starting with volume 31 in 1949 Erich von Holst (behavioral research and neurobiology) and Hans Hermann Weber (muscle physiology) replaced him to share von Frisch's (sensory biology) editorial work. In 1960 Hansjochem Autrum replaced Erich von Holst and internationalized the board in 1966. Since then, when looking at section A alone, many names illustrious in sensory and neuro- biology and neuroethology are found among the members of the editorial board: Adrian Horridge, Donald Kennedy, Ladd Prosser, Arthur W. Martin, Bernd Linzen, Robert R. Capranica, Martin Lindauer, Walter Heiligenberg, Gerhard Neuweiler, Barry Frost, and of course our present editorial crew. They all substantially contributed to keep the Journal's scientific standards high. The oldies among those presently serving on the Editorial Board are myself (since 1989), John Hildebrand (since 1990) and Peter Narins (since 1995). We are happy to also have Ken Arikawa, Uwe Homberg, Alison Mercer, Hans-Joachim Pflüger, and Günther Zupanc in the crew, so that apart from the representation of different fields of research we have members from five nations on the Editorial Board.

\section{Organismic biology and a broad range of approaches}

From its beginning the Journal of Comparative Physiology $A$ has been championing an integrative approach to research. At least in some important aspect such an approach focuses on entire organisms, both invertebrate and vertebrate. It strives to understand their behavior and evolution and the adaptations to their species-specific lives in their species-specific habitat. Integrative biologists today apply cutting edge technologies at all levels of organization, from molecular to whole organisms and indeed animal societies. Accordingly, the Journal of Comparative Physiology A welcomes studies on all levels of organization.

Putting aside the classical division between morphology and physiology, anatomical and structural studies adding to our understanding of mechanisms (relevant in sensory, neural and behavioral physiology and behavioral ecology) are highly welcome, as are studies based on genetics. There are recent and ongoing dramatic changes in our understanding of the ways which lead from genes to the phenotype. Increasingly we are learning that the genome is under substantial influence of higher levels of organization. Thus, a perspective which in essence is more organismic than molecular has become imperative in this particular context as well. 


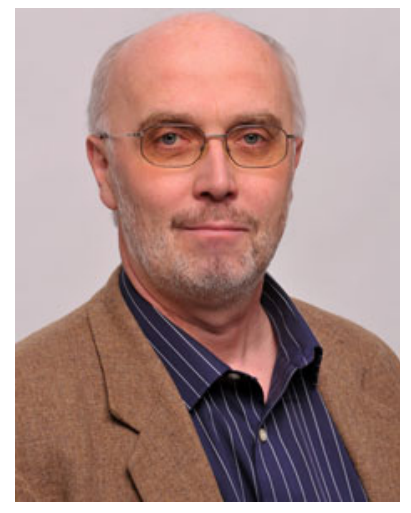

Günther K. H. Zupanc

\section{The future}

That said I would like to add that the Journal of Comparative Physiology A is wide open for inter- and transdisciplinary work. The most original and novel discoveries all too often happen at the borderline between different fields of research and where these are crossed. The Journal of Comparative Physiology A aims to remain an important part of the ongoing spectacular progress that biology has been making during the last decades and will continue to make in the decades to come.

The world of scientific publishing and indeed communication in general has changed a lot since 1924. The electronic version clearly has overtaken the printed version and the transition to open-access publishing is well on its way. Apart from all of this, however, the quality and originality of science, more than the fashionable evaluation of excellence by mere numbers, should continue to be the main reason for taking notice of this Journal's contents and for remembering it. The crew behind the Journal of Comparative Physiology A will try hard to follow this path and to make sure that the Journal remains a modern forum for outstanding research, which contributes to our understanding of the neural, sensory, ecological and hormonal mechanisms involved in natural animal behavior. 